\title{
IMPORTANCE OF PLATELET COUNT AND SEROLOGICAL MARKERS IN DIAGNOSING DENGUE INFECTION WITH SPECIAL REFERENCE TO NS1
} ANTIGEN

\author{
Saurabh G. Agarwal ${ }^{1}$, Atul R. Rukadikar², Avinash Laghawe3 ${ }^{3}$, Apoorva Tripathi ${ }^{4}$
}

\section{HOW TO CITE THIS ARTICLE:}

Saurabh G. Agarwal, Atul R. Rukadikar, Avinash Laghawe, Apoorva Tripathi. "Importance of Platelet Count and Serological Markers in Diagnosing Dengue Infection with Special Reference to NS1 Antigen". Journal of Evolution of Medical and Dental Sciences 2014; Vol. 3, Issue 10, March 10; Page: 2543-2547,

DOI: $10.14260 /$ jemds/2014/2170

ABSTRACT: INTRODUCTION: Dengue is an acute viral infection with potential fatal complications. Specific antibody detection has been the mainstay of diagnosis which is prone for both false positive and false negative reactions. The newer parameter NS1 appears to be highly specific and reliable for diagnosis of dengue infection from the first day of fever. Platelet count is the only accessory test for diagnosis of dengue infection in the peripheral laboratories. Therefore, study was done to evaluate the importance and association of platelet counts against NS1 and IgM/IgG in dengue infections. MATERIALS AND METHODS: Serum samples from clinically suspected dengue cases were tested for NS1, IgM and IgG by immunochromatography-based test. Platelet counts were obtained for all positive cases and dengue seronegative cases of fever served as controls. Test results of denguespecific parameters were compared against platelet counts. The results were subjected to statistical analysis. RESULTS: Of 159 samples tested, 17 were positive for one or more dengue parameters. Of the 17, 05 were positive for NS1 only, 06 showed IgM only while 01 showed IgG only. More than one marker was detected in the remaining 05 samples. Thrombocytopenia was more consistently associated whenever NS1 was detected compared to antibody detection (P value <0.001). CONCLUSIONS: Inclusion of NS1 in the diagnosis of dengue increases the detection rate significantly. In cases of fever, thrombocytopenia is more consistently found in dengue positive rather than dengue negative subjects. It correlates well when NS1 and IgM are detected simultaneously.

KEYWORDS: Dengue, IgM, IgG, NS1, thrombocytopenia.

INTRODUCTION: Dengue is an acute, potentially fatal viral infection that can culminate into dengue hemorrhagic fever (DHF) and dengue shock syndrome (DSS). It is caused by four serotypes of dengue virus (DV), namely DEN-1, DEN-2, DEN-3 and DEN-4 belonging to genus Flavivirus and family Flaviviridae. It is spread through the bite of infected Aedes aegypti mosquito. ${ }^{1}$ Most primary infections are uneventful. Infection with one serotype confers an individual life-long immunity to that serotype and cross-reactivity to the other serotypes. The complications like DHF and DSS are usually attributed to this cross-reactivity. ${ }^{1,2}$ Dengue is almost endemic throughout India. The resource poor health care system has to depend upon simple to perform and easy to interpret laboratory tests for diagnosis. It is known that early and specific diagnosis of DHF or DSS followed by supportive therapy reduces morbidity and mortality. ${ }^{3}$ The variability in the clinical illness associated with dengue infection (DI) cannot be accommodated in a single clinical definition. However, confirmation of DI is the most essential pre-requisite in the management of complications. ${ }^{4}$ The 'gold standard' tests for identification of DI are not within the reach of peripheral and even most tertiary care laboratories. Detection of dengue specific IgM/IgG has been the mainstay of diagnosis of DI. Antibody detection is 
an indirect method of diagnosis and, therefore, is prone to false positive as well as false negative results. ${ }^{5}$ Of late; non-structural protein 1 (NS1) detection is available for diagnosis of DI. ${ }^{6}$ NS1 detection is reported to be sensitive as well as highly specific. ${ }^{7}$ Apart from the dengue specific parameters, platelet count is the only accessory laboratory test available in the peripheral areas that can support the diagnosis of DHF or DSS. ${ }^{8}$ Keeping in mind the logistic constraints of healthcare system in the peripheral areas, we tried to correlate the platelet counts and immunochromatography (ICT)-based dengue serology tests.

MATERIAL AND METHODS: The study was conducted at Chirayu Medical College and Hospital, Bhopal from January 2013 to December 2013 after receiving permission from the institutional ethical committee. A total of 159 serum samples from clinically suspected dengue fever irrespective of age and sex were collected. Since our laboratory works round the clock, the samples were tested immediately for NS1, IgM and IgG by Immunochromatograhic test (ICT). The tests were performed strictly as per the manufacturer's instructions. Platelet counts of all the cases positive for any of the dengue parameter were recorded. Platelet counts were also recorded in cases of fever that were negative for any of the dengue parameter. No healthy controls were included in the study.

RESULTS: Of the 159 serum samples tested, a total of 17 specimens were tested positive for either one or more of the three markers (NS1, IgM and IgG) tested. Of the 17 serum samples, 05 (29.41\%) patients were positive for NS1 only, 06 (35.29\%) positive for IgM only, while 01(05.88\%) patients had only IgG. More than one marker was detected in the remaining 05 (29.41\%) samples (Table 1).

Platelet count less than $1,00,000 / \mathrm{ml}$ was noticed in 12 cases $(70.58 \%)$. Of the 142 cases presenting with fever that were negative for any of the dengue-specific parameters by ICT, none had showed thrombocytopenia. When the results were subjected to statistical treatment, this difference was found to be statistically significant, P value being less than 0.001. (Table 2) (Table 3).

DISCUSSION: For a long time detection of dengue-specific IgG/IgM has been the mainstay of diagnosis of DI. The dengue-specific antibodies begin to appear only around fifth day of fever in primary infection. ${ }^{5}$ Even in most secondary infections, both the IgM and IgG type antibodies cannot be recorded before third day. ${ }^{9}$ Therefore, there is always a window period, both in primary and secondary DI when only antibodies are tested. The new parameter, NS1 antigen, is detectable from day 1 of fever both in primary and secondary infections. It is important to note that NS1 is shown to be highly specific viral marker making it extremely reliable parameter for the diagnosis of DI from day 1 of the fever. ${ }^{10}$

The distribution of various dengue specific parameters is shown in (Table 1). Of the 159 cases, 05 (29.41\%) were positive for only NS1 antigen. This finding is consistent with the study done by Kulkarni RD et al ${ }^{11}$ and Datta $S$ et al ${ }^{10}$ in which $30 \%$ and $23.3 \%$ cases were positive for only NS1 antigen respectively. Only IgM was positive in 06 (35.29\%) cases. This is in consistent with the study conducted by Ukey PM et al ${ }^{12}$ in which $31.3 \%$ patients were serologically positive for dengue infection. This indicates that, dengue-specific IgM is a very good indicator of recent infection. IgG was positive in only $01(05.88 \%)$ case which showed past infection with dengue. NS1 in combination with IgM were positive in $01(05.88 \%)$. No sample was found to be positive for both NS1 and IgG. Both IgM and IgG were found to be positive for 04 (23.52\%) cases indicating acute on chronic infection. 
We tried to find the association of dengue parameter positivity with thrombocytopenia. The comparison of platelet counts with different dengue specific parameters is shown in (Table 2). Of the 17 cases, $12(70.58 \%)$ showed thrombocytopenia. In 05 cases that were positive for NS1, thrombocytopenia was evident in $04(80.00 \%)$ cases. In contrast, when IgM and IgG antibodies were considered for the diagnosis of DI, thrombocytopenia was noted only in IgM antibody (83.33\%). Association of thrombocytopenia with NS1and IgM was found to be $100 \%$ while association of thrombocytopenia with IgM and IgG was evident in 50\% cases.

Platelet counts are decreased in several other conditions like some viral infections other than dengue, drug induced thrombocytopenia, collagen vascular diseases, idiopathic thrombocytopenia etc. ${ }^{3}$ We therefore, tried to correlate platelet counts in cases of fever that tested negative for any of the dengue parameters (Table 3). In 142 cases of fever, in which none of the dengue parameters was positive, thrombocytopenia was not noted. Applying Statistical analysis, it was found that association of thrombocytopenia and dengue parameter was significantly higher with p value less than 0.001 .

This study has been carried out at a tertiary care teaching hospital. It is worth mentioning here that most tertiary care teaching hospitals lack in viral culture setup. Therefore, applying gold standard tests in studies related to viral infections is out of reach of these centers. Dengue is an infection that is present in urban, semi-urban and rural areas. Our healthcare system is extremely resource poor. Top class technological backup is available only at very few elite laboratories situated in big cities. It is important to conduct studies in the peripheral centers where the laboratory has to function without great technological backup and still is expected to provide reasonable opinion to the clinician in the management of infections like dengue. ${ }^{11}$

The limitation of the present study was that enzyme linked immunosorbent assay (ELISA) for qualitative or quantitative detection or Polymerase Chain Reaction (PCR) could not be used. ELISA has higher sensitivity than ICT-based tests. ${ }^{13}$ Inclusion of ELISA in this study could have given us an opportunity to comment on the efficacy of ICT to identify DI. Most of the cases coming to our hospital were referred from various places and had received a few days treatment before reaching this hospital. The precise day of fever at the time of conducting the test could not be obtained in a large number of cases. In spite of this, NS1 only was positive in 30\% cases. Given an opportunity to test every case of fever on day 1, more number of cases could have been picked up by NS1. It is shown that the titres of NS1 represent the viral load and the viral load is directly proportional to complications. ${ }^{7}$ It can be logically inferred that in complication prone cases, i.e. having higher viral load, detection of NS1 will be easier because of higher NS1 levels. This would reduce the chances of false negativity by a less sensitive test like ICT. ${ }^{11}$

CONCLUSION: Inclusion of NS1 must be included for evaluation of all cases of fever, either in endemic or non-endemic areas. The ease, speed and dependability of ICT make it an excellent tool in addressing this potentially fatal, epidemic prone infection that has become an important public health problem in our country. One can never forget the fact that dengue often breaks out in resource poor peripheral areas where ICT-based tests could be the only support available.

\section{REFERENCES:}

1. Guzmán MG, Kourí G. Dengue: An update. Lancet Infect Dis 2001; 2: 33-42.

2. Martina BE, Koraka P, Osterhaus A. Dengue Virus Pathogenesis: An Integrated View. Clin Microbiol Rev 2009; 22:564-81. 
3. Peters CJ. Infections caused by arthropod- and Rodent -borne viruses. In: Fauci AS, editor. Harrison's principles of Internal Medicine. 17 th ed. New York: McGraw-Hill Medical Publishing Division; 2008. p. 1226-39.

4. World Health Organization. Dengue haemorrhagic fever: Diagnosis, treatment, prevention and control (second edition). Geneva, Switzerland: Chapter 4, Laboratory diagnosis; 1997. p. 34-47

5. Peeling RW, Artsob H, Pelegrino JL, Buchy P, Cardosa MJ, Devi S, et al. Evaluation of diagnostic tests: Dengue. Nat Rev Microbiol 2010; 8: S30-7.

6. Young PR, Hilditch PA, Bletchly C, Halloran W. An antigen capture enzyme-linked immunosorbent assay reveals high levels of the dengue virus protein NS1 in the sera of infected patients. J Clin Microbiol 2000; 38:1053-7.

7. Libraty DH, Young PR, Pickering D, Endy TP, Kalayanarooj S, Green S, et al. High Circulating Levels of the Dengue Virus Nonstructural Protein NS1 Early in Dengue Illness Correlate with the Development of Dengue Hemorrhagic Fever. J Infect Dis 2002; 186:1165-8.

8. World Health Organization. Dengue haemorrhagic fever: Diagnosis, treatment, prevention and control. 2 nd edition. Geneva, Switzerland: Chapter 2, Clinical Diagnosis, 1997. p. 12-23.

9. Schilling S, Ludolfs D, An LV, Schmitz H. Laboratory diagnosis of primary and secondary dengue infection. J Clin Virol 2004; 31:179-84.

10. Datta S, Wattal C. Dengue NS1 antigen detection: A useful tool in early diagnosis of dengue virus infection. Indian J Med Microbiol 2010; 28:107-10.

11. Kulkarni RD, Patil SS et al. Association of platelet count and serological markers of dengue infection-importance of NS1 antigen. Indian Journal of Medical Microbiology 2011; 29(4): 359-62.

12. Ukey PM, Bondade SA et al. Study of seroprevalence of Dengue Fever in Central India. Indian J Community Med 2010; 35(4):517-9.

13. Hang TV, Nguyet MN, Trung TD, Tricou V, Yoksan S, Minh ND, et al. Diagnostic Accuracy of NS1 ELISA and Lateral Flow Rapid Tests for Dengue sensitivity, Specificity and Relationship to Viraemia and Antibody Responses. PLoS Negl Trop Dis 2009; 3: e360. Shrivastava A, Dash PK, Tripathi NK, Sahni AK, Gopalan N, Lakshmana Rao PV. Evaluation of a commercial dengue NS1 enzyme-linked immunosorbent assay for early diagnosis of dengue infection. Indian J Med Microbiol2011; 29:51-5.

\begin{tabular}{|l|c|c|}
\hline \multicolumn{1}{|c|}{ PARAMETER } & TOTAL & PERCENTAGE \\
\hline NS1 only & 05 & $29.41 \%$ \\
\hline IgM only & 06 & $35.29 \%$ \\
\hline IgG only & 01 & $05.88 \%$ \\
\hline NS1 \& IgM & 01 & $05.88 \%$ \\
\hline NS1 \& IgG & 00 & $00.00 \%$ \\
\hline IgM \& IgG & 04 & $23.52 \%$ \\
\hline \multicolumn{1}{|c|}{ Total } & $\mathbf{1 7}$ & $\mathbf{1 0 0 . 0 0 \%}$ \\
\hline
\end{tabular}

TABLE 1: COMPARISION OF VARIOUS DENGUE SPECIFIC

PARAMETERS IN DIAGNOSING DENGUE INFECTION 


\begin{tabular}{|c|c|c|c|}
\hline PARAMETER & TOTAL & $\begin{array}{c}\text { PLATELET COUNT LESS } \\
\text { THAN 1, 00, 000/ML }\end{array}$ & PERCENTAGE \\
\hline NS1 only & 05 & 04 & $80.00 \%$ \\
\hline IgM only & 06 & 05 & $83.33 \%$ \\
\hline IgG only & 01 & 00 & $00.00 \%$ \\
\hline NS1 \& IgM & 01 & 01 & $100.00 \%$ \\
\hline NS1 \& IgG & 00 & 00 & $00.00 \%$ \\
\hline IgM \& IgG & 04 & 02 & $50.00 \%$ \\
\hline Total & 17 & $\mathbf{1 2}$ & $\mathbf{7 0 . 5 8 \%}$ \\
\hline \multicolumn{4}{|c|}{ TABLE 2: COMPARISION OF PLATELETCOUNT } \\
\hline \multicolumn{4}{|c}{ WITH VARIOUS DENGUE PARAMETERS } \\
\hline
\end{tabular}

\begin{tabular}{|c|c|c|c|}
\hline & $\begin{array}{c}\text { DENGUE POSITIVE } \\
\text { CASES }\end{array}$ & $\begin{array}{c}\text { DENGUE NEGATIVE } \\
\text { CASES } \\
\end{array}$ & TOTAL \\
\hline $\begin{array}{c}\text { PLATELET COUNT } \\
\text { LESS THAN } \\
1,00,000 / \mathrm{ML} \\
\end{array}$ & $12(100 \%)$ & $00(00.00 \%)$ & $12(07.54 \%)$ \\
\hline $\begin{array}{c}\text { PLATELET COUNT } \\
\text { MORE THAN } \\
1,00,000 / \mathrm{ML} \\
\end{array}$ & $05(03.40 \%)$ & $142(96.59 \%)$ & $147(92.45)$ \\
\hline TOTAL & $17(10.69 \%)$ & $142(89.30 \%)$ & $159(100 \%)$ \\
\hline \multicolumn{4}{|c|}{$\mathrm{p}$ value $<0.001$ (Highly Significant), Chi Square $\left(X^{2}\right)=108.4$} \\
\hline
\end{tabular}

\section{AUTHORS:}

1. Saurabh G. Agarwal

2. Atul R. Rukadikar

3. Avinash Laghawe

4. Apoorva Tripathi

\section{PARTICULARS OF CONTRIBUTORS:}

1. Assistant Professor, Department of Microbiology, Chirayu Medical College and Hospital, Bhopal.

2. Assistant Professor, Department of Microbiology, Chirayu Medical College and Hospital, Bhopal.

3. Associate Professor, Department of Microbiology, Chirayu Medical College and Hospital, Bhopal.
4. Associate Professor, Department of Microbiology, Chirayu Medical College and Hospital, Bhopal.

\section{NAME ADDRESS EMAIL ID OF THE}

\section{CORRESPONDING AUTHOR:}

Dr. Atul R. Rukadikar,

Assistant Professor,

Chirayu Medical College and Hospital,

Bhopal.

E-mail: atulruks@gmail.com

Date of Submission: 11/02/2014.

Date of Peer Review: 12/02/2014.

Date of Acceptance: 21/02/2014.

Date of Publishing: 05/03/2014. 